\title{
A case of mutism on emergence from general anesthesia
}

\author{
Usha Gurunathan $^{1,2} \cdot$ Harish Iswariah ${ }^{1,2}$
}

Received: 18 January 2016 / Accepted: 1 February 2016 / Published online: 12 February 2016

(C) Japanese Society of Anesthesiologists 2016

Keywords General anaesthesia $\cdot$ Recovery

To the Editor:

A 56-year-old female presented for an elective umbilical hernia repair under general anesthesia in our hospital. She was a smoker and had ongoing chronic pain and stress issues. Her medical records documented an inability to speak following the most recent surgery, attributed to ketamine. Standard general anaesthesia was administered and extubation was uneventful. Soon after, the patient developed intermittent stridors that settled following intravenous midazolam $0.5 \mathrm{mg}$ and normal saline nebulisation. We found her stuporous with no attempt to speak and no sign of distress. After an hour, the patient started communicating through writing. Since no organic cause was obvious, it was initially suspected to be functional aphaemia; however, she also had weakness in her limbs. There were no focal neurological signs and pupillary reflexes were normal. Interestingly, around midnight, her muscle power and speaking ability returned to the same extent as before surgery. Her further stay in hospital was unremarkable.

Mutism, a rare postoperative outcome, is an 'inability or unwillingness to speak' in a conscious patient due to functional or organic causes [1], as opposed to aphasia which is a 'disorder of language processing' due to brain

Usha Gurunathan

usha.gurunathan@health.qld.gov.au

1 Department of Anesthesia and Perfusion Services, The Prince Charles Hospital, Rode Road, Chermside, Brisbane, QLD 4032, Australia

2 Department of Surgery, The Prince Charles Hospital, Rode Road, Chermside, Brisbane, QLD 4032, Australia dysfunction [2]. Only two similar cases had been reported previously following non-neurological surgeries [3, 4]. In our case, following further psychiatric consultation it was diagnosed that this mutism could either be a symptom of acute catatonia due to the presence of stupor, waxy flexibility and indifference to external stimuli that had responded to benzodiazepines [5] or it might have been a manifestation of conversion disorder following surgical stress. Conversion disorder is a type of somatoform disorder in which physical symptoms may not have a clear apparent organic etiology. It can have varied manifestations such as paralysis, aphonia, ataxia, vision loss, etc. [6]. Background psychiatric issues and surgical stress could have precipitated the abnormal reaction.

\section{References}

1. Aggarwal A, Sharma DD, Kumar R, Sharma RC. Mutism as the presenting symptom: three case reports and selective review of literature. Indian J Psychol Med. 2010;32:61-4.

2. Damasio AR. Aphasia. N Engl J Med. 1992;326:531-9.

3. Narayanan A, Tawfic QA, Kausalya R, Mohammed AK. Speechless after general anaesthesia for caesarean section. Middle East J Anaesthesiol. 2012;21:739-42.

4. Kati I, Demirel CB, Anlar O, Huseyinoglu UA, Silay E, Elcicek $\mathrm{K}$. An unusual complication of total intravenous anesthesia: mutism. Anesthesia Analgesia. 2003;96:168-70 (table of contents).

5. Weder ND, Muralee S, Penland H, Tampi RR. Catatonia: a review. Ann Clin Psychiatry. 2008;20:97-107.

6. Roffman JL, Stern TA. Conversion disorder presenting with neurologic and respiratory symptoms. Prim Care Companion J Clin Psychiatry. 2005;7:304-6. 